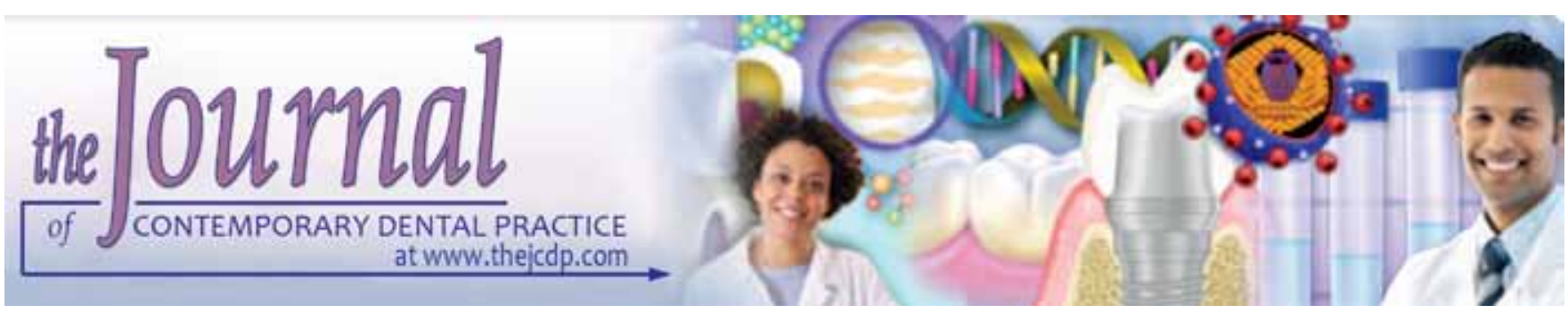

\title{
Influence of Different Types and Concentrations of Chemical Catalysts on Dental Bleaching Efficiency
}

\author{
${ }^{1}$ Carlos Rocha Gomes Torres, ${ }^{2}$ Carolina Anne Guimarães, ${ }^{3}$ Zulene Eveline Abreu Ribeiro, ${ }^{4}$ Alessandra Bühler Borges
}

\begin{abstract}
The objective of this study was to evaluate the effects of different types and concentrations of chemical catalysts on the efficiency of $35 \%$ hydrogen peroxide gel on dental bleaching. Enameldentin disks were obtained from bovine incisors and the initial color was assessed. The groups were divided according to the type and concentration of catalyst added to an experimental gel: ferrous sulphate (FS) $(0.001,0.002$ and $0.003 \%)$; ferrous gluconate (FG) $(0.01,0.02$ and $0.03 \%)$; ferric chloride (FC) $(0.01,0.02$ and $0.03 \%)$; manganese gluconate (MG) $(0.01,0.02$ and $0.03 \%$ ); and manganese chloride (MC) $(0.01,0.02$ and $0.03 \%)$. The positive control $(\mathrm{PC})$ group received the bleaching gel without any catalyst, while in the negative control (NC) the specimens remained in artificial saliva. Three applications of the bleaching gels were performed for 10 minutes each, repeated after 7 days. Color assessments were performed 7 days after the first session and 7 days after the second. The specimens were stored in artificial saliva and assessed again after 1 year. The data were analyzed by parametric analysis of variance and Tukey's test. Some of the chemical catalysts tested were effective in reducing the yellowish color of the samples in relation to the positive control group after 1 and 2 applications and diminished the color relapse over time. After 1 year, the FS was the most effective catalyst tested. We concluded that some chemical catalysts increased the efficiency of dental bleaching.
\end{abstract}

Keywords: Catalyst, Color, Dental bleaching, Esthetic, Hydrogen peroxide.

How to cite this article: Torres CRG, Guimarães CA, Ribeiro ZEA, Borges AB. Influence of Different Types and Concentrations of Chemical Catalysts on Dental Bleaching Efficiency. J Contemp Dent Pract 2015;16(11):893-902.

Source of support: São Paulo Research FoundationFAPESP, Process: 2010/50912-8

Conflict of interest: None

\footnotetext{
${ }^{1-4}$ Department of Restorative Dentistry, Institute of Science and Technology, São Paulo State University, São Paulo, Brazil

Corresponding Author: Carlos Rocha Gomes Torres Associate Professor, Department of Restorative Dentistry Institute of Science and Technology, São Paulo State University, São Paulo Brazil, Phone: 5512 3947-9376, e-mail: carlosrgt@gmail.com
}

\section{INTRODUCTION}

Nowadays, dental bleaching is one of the most requested esthetic treatments in dentistry. It is based on the capacity of hydrogen peroxide to penetrate the tooth structure and to produce the oxidation of dark organic molecules known as chromogens. ${ }^{1}$ Hydrogen peroxide is able to diffuse through the interprismatic and periprismatic enamel spaces, inside porosities varying from 10 to 100 angstrom. $^{2}$ Because of its inherent instability, it decomposes and produces free radicals, such as hydroxyl $\left(\mathrm{HO}^{\circ}\right)$ and peri-hydroxyl $\left(\mathrm{HO}_{2}{ }^{\circ}\right)$, as can be seen in the Equations. ${ }^{1-3}$ They are strong oxidizing agents and reacts with the macromolecular chains of chromogens inside the tooth structure. ${ }^{3}$

$$
\begin{aligned}
& \mathrm{H}_{2} \mathrm{O}_{2} \leftrightarrow \mathrm{H}^{+}+\mathrm{HO}_{2}^{-} \\
& \mathrm{HO}_{2}^{-}+\mathrm{H}_{2} \mathrm{O}_{2} \rightarrow \mathrm{HO}_{2}^{\bullet}+\mathrm{HO}^{\bullet}+\mathrm{HO}^{-} \\
& \mathrm{HO}^{\bullet}+\mathrm{H}_{2} \mathrm{O}_{2} \rightarrow \mathrm{HO}_{2}^{\bullet}+\mathrm{H}_{2} \mathrm{O}
\end{aligned}
$$

Bleaching can be performed by means of the home bleaching technique, using low concentrated hydrogen or carbamide peroxide gels as the oxidizing agent for longer periods, or can be done using the in-office technique, which requires high concentrated hydrogen peroxide products, applied for shorter periods. ${ }^{4}$ Generally, one session of in-office bleaching is not enough to reach the desired effect, ${ }^{5}$ which makes many appointments necessary until a satisfactory effect can be reached. ${ }^{4}$ Therefore, it is very important with this technique to get a more pronounced effect in a shorter time possible, being that the reason of using high concentration of oxidizing agents in products designed for in-office use, since the amount of free radicals in a hydrogen peroxide solution increases with the increase of peroxide concentration. ${ }^{3}$

Taking into account these aspects, it is very important to search for ways of increasing the efficiency of this process, stimulating the dissociation of the hydrogen peroxide and consequently the formation of free radicals. 
Usually, physical activation methods have been applied for providing energy for the reaction. This has been done through direct heat diffusion, using electric heating devices or heated hand instruments in former times or, more recently, using light sources, such as the blue light from QTH and plasma arc lamps, light emitting diodes (LED), or laser. ${ }^{4}$ On the other hand, the efficacy of light activation of bleaching gels has been questioned, and some studies have pointed out that its benefits are limited or nonsignificant. ${ }^{4,6}$ Another point is that the heating of the bleaching gel also produces the heating of the pulpal tissue, increasing the occurrence of postoperative sensitivity and the risk of irreversible pulpal damage, reducing the limits of temperature applied. ${ }^{4}$ Additionally, heating of the bleaching gel can increase its penetration through enamel and dentin, increasing the potential of pulpal damage. ${ }^{7}$ Although this increase of penetration would improve the dentin bleaching, which has a high influence on the final color change, a higher diffusion would increase the oxidative stress of the tissue, which can negatively affect the metabolism of the pulpal cells. ${ }^{4,8}$

Hydrogen peroxide is a very unstable molecule which dissociates when in contact with the tooth structure or organic molecules. ${ }^{9}$ One of the factors that can affect its dissociation is the $\mathrm{pH}$ of the hydrogen peroxide solution or gel. Under alkaline $\mathrm{pH}$, the formation of free radicals is more quick and intense than under acidic $\mathrm{pH} .{ }^{10-15}$ Additionally, some enzymes and salts of transition metals, such as $\mathrm{Fe}, \mathrm{Cu}, \mathrm{Cr}$, or $\mathrm{Mn}$, can act as catalyzers or intensifiers, promoting the dissociation of hydrogen peroxide molecules and formation of free radicals. ${ }^{11,16-22}$ Previous studies have shown that the association of metallic salts and bleaching gels was able to improve the dental bleaching effect. ${ }^{11,18,21-24}$ Others suggested the use of enzymes, such as peroxidases or those available from the mulberry root extract, as bleaching catalyzers. ${ }^{20,21}$

One of the main advantages of hydrogen peroxide chemical activation using a catalyst is the absence of pulpal heating during the process, reducing the aggressiveness of the procedure in relation to the use of heating sources for the physical activation. Besides that, the more intense results produced by these catalyzers probably can result in more long-term stable results, reducing the color regression. However, the kind of chemical activator which is more efficient, as well the amount to be incorporated in the formulation of the bleaching gel, are still questions to be answered. The understanding of the dynamics of this process can lead to the creation of less concentrated and more efficient bleaching gels.

The aim of this study was to evaluate the addition of different types and concentrations of chemical catalysts on the bleaching effect of experimental hydrogen peroxide gels, as well as the bleaching stability. The null hypothesis tested was that both type and concentration of the catalyst were not able to interfere with the bleaching effect of hydrogen peroxide or with color stability after 1 year.

\section{MATERIALS AND METHODS}

\section{Preparation of the Samples}

One hundred and seventy bovine incisors obtained from recently slaughtered animals were used in this study. After extraction, the root, pulpal tissue, and remaining of soft tissue were removed, and the teeth were stored in a $0.1 \%$ thymol solution at $4^{\circ} \mathrm{C}$ until required. ${ }^{8}$ Before use, the crowns were examined under stereomicroscope to certify the absence of cracks or other surface defects. ${ }^{25}$

Using a diamond covered trephine mill, 510 enamel and dentin disks $3 \mathrm{~mm}$ in diameter were obtained from the buccal surface of the teeth according to the method described by Torres et al. ${ }^{24}$ The thickness of the enamel and dentin was standardized to $1 \mathrm{~mm}$ each using a P1200 abrasive paper (Fepa-P, Extec, Enfield, CT, USA). The enamel surface was additionally polished with P2400 and P4000. The thickness of $1 \mathrm{~mm}$ was chosen because it is the mean thickness of enamel and dentin on the buccal surface of a central human incisor. ${ }^{26,27}$ After the polishing, the samples were cleaned by immersion in an ultrasonic bath for 10 minutes (Ultrasonic Cleaner, Odontobras, Ribeirao Preto, SP, Brazil). The samples were stored in a $0.1 \%$ thymol solution for 7 days for rehydration.

\section{Color Reading}

The baseline colors of all samples were evaluated using a reflectance spectrophotometer (CM-2600d, Konica Minolta, Osaka, Japan). The settings of the device were adjusted in Small Area View (SAV), D65 standard illuminant, $100 \% \mathrm{UV}$ included, observer angle of $2^{\circ}$ and specular component included (SCI). Before readings, the device was calibrated with black and white standards. The color data obtained were analyzed according to CIE Lab color system, using the software Spectramagic NX (Konica Minolta, Osaka, Japan). ${ }^{28}$ The samples were positioned inside a specimen holder made with white rubber, with a fitting area $3 \mathrm{~mm}$ in diameter and $2 \mathrm{~mm}$ depth. At the bottom of the fitting area a standard white background (CERAM, Stoke-on-Trent, Staffordshire, UK) was positioned, as suggested by Lee et al. ${ }^{29}$ In order to produce an optical contact between the dentin and the background, a small drop of polyethylene glycol 400 (LabSynth, São Paulo, SP, Brazil) was applied between 
them. This substance has a refractive index close to the tooth structure, reducing the light refraction at the interface (1.47). ${ }^{30,31}$

The samples were removed from the thymol solution, dried with absorbent paper, and placed inside the specimen holder. The excess of optical contact was quickly removed with absorbent paper and the color reading was performed. The device was adjusted for three consecutive readings, and the mean values of $L^{*}, a^{*}$, and $b^{*}$ coordinates were recorded.

\section{Distribution of Groups}

The samples were stratified into the groups according to $b^{*}$ values, in order to have a homogeneous distribution of the samples in relation to their yellowish color. Two control groups were prepared $(n=30)$. A positive control group (PC) was bleached using an experimental 35\% hydrogen peroxide gel without any activator. The negative control group (NC) was immersed in artificial saliva during the whole experiment, replaced each 24 hours. The artificial saliva used was prepared according to Gohring et $\mathrm{al}^{32}$ and adjusted to $\mathrm{pH} 7$.

The other samples were divided into five groups, according to the chemical catalyst activator tested in association with the experimental 35\% hydrogen peroxide bleaching gel $(\mathrm{n}=90)$. The catalyst tested were ferrous gluconate (FG), ferrous sulphate (FS), ferric chloride (FC), manganese gluconate (MG), and manganese chloride (MC). Each group was divided into three subgroups, according to the concentration of each catalyst. The concentrations $0.01 \%(1), 0.02 \%$ (2), and $0.03 \%$ (3) were tested for FG, FC, MG and MC. The concentrations of $0.001 \%(1), 0.002 \%(2)$, and $0.003 \%$ (3) were tested for FS. These concentrations were obtained in pilot studies, where it was observed that with those, the catalysts were able to produce a visible release of oxygen bubbles after the mixture with peroxide, but this release was discreet, keeping the bleaching gel from becoming a foam. ${ }^{23,24,33,34}$ Additional information about the catalysts tested can be seen in Table 1.

\section{Bleaching Treatment}

An experimental 35\% hydrogen peroxide bleaching gel formulation was prepared and used for all groups. This gel was obtained from the mixture of two solutions. The first solution was composed of $50 \%$ hydrogen peroxide and an acrylic thickener, while the second one was an alkaline solution containing or not the tested chemical activator. The same peroxide solution was used for all experimental and positive control groups. For each subgroup, the catalysts were added to the alkaline solution. In order to check if the correct initial concentration of hydrogen peroxide was present at the original $50 \% \mathrm{w} / \mathrm{w}$ solution (Dinamica Quimica Contemporanea Ltda, Diadema, SP, Brazil), a titration with potassium permanganate $0.1 \mathrm{~N}$ was performed. A primary standard of sodium oxalate was used to standardize the $\mathrm{KMnO}_{4}$ solution. ${ }^{9,35}$

The 35\% hydrogen peroxide gel was obtained by mixing three parts of the hydrogen peroxide solution with one part of the alkaline/catalyst solution, measured by volume using micropipettes. The solutions were poured inside a mixing well and mixed with a plastic spatula in a rotation movement. The $\mathrm{pH}$ of the solutions and the gel obtained with the combination are presented in Table 2.

In order to restrain the bleaching gel application on the enamel surface, preventing its contact with the internal part of the enamel and dentin, the samples were positioned inside a silicone specimen holder, which consisted of cylindrical wells with the same dimensions of the samples. A layer of approximately $2 \mathrm{~mm}$ of gel was applied over the surface for 10 minutes. After that, the gel was removed and a new layer applied. This procedure was repeated one more time for a total session time of 30 minutes. After the last gel was removed, the samples were washed in ultrapure water and immersed in $2 \mathrm{ml}$ of artificial saliva inside Eppendorf tubes and kept at $37^{\circ} \mathrm{C}$ for 7 days. The artificial saliva was changed every 24 hours. The color was evaluated again at the end of the 7 days and the bleaching procedure was repeated. The samples were immersed in artificial saliva for 7 more

Table 1: Chemical catalyst tested

\begin{tabular}{|c|c|c|c|c|}
\hline Groups & Catalyst & Formula & Manufacturer & CAS \\
\hline FS & $\begin{array}{l}\text { Ferrous (II) sulphate } \\
\text { heptahydrate }\end{array}$ & $\mathrm{FeSO}_{4} \cdot 7 \mathrm{H}_{2} \mathrm{O}$ & LabSynth Ltda., Diadema, SP, Brazil & $77-82-63-0$ \\
\hline FG & $\begin{array}{l}\text { Ferrous (II) gluconate } \\
\text { dihydrate }\end{array}$ & $\left(\mathrm{CH}_{2} \mathrm{OH}(\mathrm{CHOH})_{4} \mathrm{COO}\right)_{2} \mathrm{Fe} .2 \mathrm{H}_{2} \mathrm{O}$ & $\begin{array}{l}\text { Gluconal FE Pharma, Purac, } \\
\text { Campos dos Goytacazes, RJ, Brazil }\end{array}$ & $12389-15-0$ \\
\hline $\mathrm{FC}$ & $\begin{array}{l}\text { Ferric (III) chloride } \\
\text { hexahydrate }\end{array}$ & $\mathrm{FeCl}_{3} \cdot 6 \mathrm{H}_{2} \mathrm{O}$ & $\begin{array}{l}\text { Vetec Química Fina, Rio de Janeiro, } \\
\text { RJ, Brazil }\end{array}$ & $10025-77-1$ \\
\hline MG & $\begin{array}{l}\text { Manganese (II) gluconate } \\
\text { dihydrate }\end{array}$ & $\left(\mathrm{CH}_{2} \mathrm{OH}(\mathrm{CHOH})_{4} \mathrm{COO}\right)_{2} \mathrm{Mn} \cdot 2 \mathrm{H}_{2} \mathrm{O}$ & $\begin{array}{l}\text { Gluconal MN-P, Purac, Campos dos } \\
\text { Goytacazes, RJ, Brazil }\end{array}$ & $6485-39-8$ \\
\hline MC & $\begin{array}{l}\text { Manganese (II) chloride } \\
\text { tetrahydrate }\end{array}$ & $\mathrm{MnCl}_{2} \cdot 4 \mathrm{H}_{2} \mathrm{O}$ & $\begin{array}{l}\text { Vetec Química Fina, Rio de Janeiro, } \\
\text { RJ, Brazil }\end{array}$ & $13446-34-9$ \\
\hline
\end{tabular}


Table 2: $\mathrm{pH}$ values of solutions and bleaching gels

\begin{tabular}{|c|c|c|c|c|c|c|c|}
\hline \multirow{3}{*}{$\begin{array}{l}\text { Peroxide } \\
\text { solution }\end{array}$} & \multicolumn{4}{|c|}{ Alkaline solution } & \multicolumn{3}{|c|}{ Bleaching gels } \\
\hline & \multirow[b]{2}{*}{ Catalyst } & \multicolumn{3}{|c|}{ Concentration } & \multicolumn{3}{|c|}{ Concentration } \\
\hline & & 1 & 2 & 3 & 1 & 2 & 3 \\
\hline \multirow[t]{6}{*}{1.41} & FS & 9.75 & 9.77 & 9.65 & 5.50 & 5.48 & 5.47 \\
\hline & FG & 9.83 & 9.81 & 9.81 & 5.58 & 5.63 & 5.56 \\
\hline & $\mathrm{FC}$ & 9.66 & 9.59 & 9.59 & 5.63 & 5.59 & 5.55 \\
\hline & MG & 9.76 & 9.72 & 9.71 & 5.49 & 5.59 & 5.55 \\
\hline & $\mathrm{MC}$ & 9.65 & 9.65 & 9.62 & 5.85 & 5.57 & 5.60 \\
\hline & None & & 9.98 & & & 5.54 & \\
\hline
\end{tabular}

days and the color evaluated again. The samples were then immersed in artificial saliva, which was changed weekly to reduce the bacterial growth that could change the $\mathrm{pH}$ of the storage solution. The color was evaluated after 1 year.

\section{Calculation of Color Change}

Taking into account that the changes of the $b^{*}$ axis are the most relevant in relation to the dental bleaching, ${ }^{36}$ representing the yellowish color reduction of the tooth structure, the changes of $b^{*}$ coordinate before and after treatments were calculated $(\Delta b)$, using the values obtained before the bleaching as a baseline. ${ }^{28}$

\section{STATISTICAL ANALYSIS}

In order to check the normal distribution of the data, the Kolmogorov-Smirnov's test was applied. The effects of the different concentrations were analyzed separately for each catalyst agent in relation to the control groups using one-way ANOVA and Tukey's test. The effect of each bleaching session and storage in saliva were analyzed separately for each concentration of activator, checking if the bleaching effect became more intense after the second session and whether some color regression occurred.

In order to find out which catalyst was more effective, the data for each chemical agent, independent of the concentration, were compared after each session and after 1 year using one-way ANOVA and Tukey's test. For all analysis, a significance level of 5\% was adopted.

\section{RESULTS}

The Kolmogorov-Smirnov's test confirmed the normal distribution of the data $(p>0.05)$. All bleached groups presented significant differences in relation to the negative control, showing the bleaching effect of the experimental gel. The results of the color change after the second session were higher than after the first. After 1 year, a color regression was observed for the positive control, compared to the results after the second session.

Table 3 shows the results for FS. It can be seen that this activator produced significantly higher effects in relation to the positive control for concentrations 2 and 3 after one application and for all concentrations after 1 year. No color regression was observed for the experimental groups.

The results for FC are shown in Table 4 . All concentrations tested produced a significant change of $b^{*}$ values in relation to the control group after the first application. After the second application and after 1 year, nonsignificant differences were observed in relation to the positive control, with the exception of concentration one after 1 year. No significant color regression was observed after 1 year for the experimental groups.

Table 5 shows the results for FG. It can be seen that this activator did not produce significant effects in relation to the positive control. Nonsignificant color regressions were observed for these experimental groups.

Table 6 shows the results for MG. Concentrations 1 and 2 showed significant differences in relation to the control group after one application. After the second application, just concentration 2 showed differences in relation the positive control. After 1 year, nonsignificant differences were observed in relation to the positive control group. All experimental groups showed color regression after 1 year in relation to the results after the second application.

The results for $\mathrm{MC}$ are shown in Table 7. Concentrations 2 and 3 showed significant differences in relation to the positive control after one application and 1 year. After

Table 3: Results of ANOVA and Tukey's test for $\Delta \mathrm{b}$ at different times using FS

\begin{tabular}{|c|c|c|c|c|c|c|c|c|c|c|c|c|c|}
\hline \multirow[b]{2}{*}{ Groups } & \multicolumn{4}{|c|}{ 1st session } & \multicolumn{4}{|c|}{ 2nd session } & \multicolumn{4}{|c|}{1 year } & \multirow[b]{2}{*}{ ANOVA $^{\bullet}$} \\
\hline & Mean & $S D$ & $\#$ & 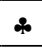 & Mean & $S D$ & $\#$ & 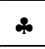 & Mean & $S D$ & $\#$ & + & \\
\hline $\mathrm{CN}$ & 1.00 & 0.49 & $A$ & a & 1.45 & 0.52 & $A$ & a & 1.37 & 0.78 & $A$ & a & $p=0.050(f=5.01)$ \\
\hline $\mathrm{CP}$ & -0.94 & 1.22 & $\mathrm{~B}$ & a & -2.25 & 1.06 & $\mathrm{~B}$ & $\mathrm{~b}$ & -1.37 & 1.18 & $\mathrm{~B}$ & a & $p=0.000^{*}(f=10.65)$ \\
\hline FS1 & -1.61 & 0.99 & $\mathrm{BC}$ & a & -2.03 & 1.16 & $\mathrm{~B}$ & $\mathrm{a}$ & -2.31 & 1.33 & $\mathrm{C}$ & a & $p=0.057(f=2.93)$ \\
\hline FS2 & -1.90 & 1.01 & C & a & -2.73 & 1.35 & $\mathrm{~B}$ & $b$ & -2.99 & 1.65 & $\mathrm{C}$ & $\mathrm{b}$ & $p=0.005^{*}(f=5.60)$ \\
\hline FS3 & -1.91 & 1.24 & $\mathrm{C}$ & a & -2.26 & 1.20 & $\mathrm{~B}$ & a & -2.66 & 1.34 & $\mathrm{C}$ & a & $p=0.067(f=2.77)$ \\
\hline ANOVA ${ }^{*}$ & \multicolumn{4}{|c|}{$p=0.000^{*}(f=45.66)$} & \multicolumn{4}{|c|}{$p=0.000^{*}(f=77.69)$} & \multicolumn{5}{|c|}{$p=0.000^{*}(f=59.95)$} \\
\hline
\end{tabular}

\#Different capital letters in columns indicate differences among the groups for each evaluation; "Different small letters in rows indicate differences among the readings for each group; ${ }^{\star R}$ Results of ANOVA for the comparison among the groups for each evaluation (df $=4$ ); -Results of ANOVA for the comparison among the readings for each group ( $\mathrm{df}=2$ ); ${ }^{*}$ Significant differences 
Influence of Different Types and Concentrations of Chemical Catalysts on Dental Bleaching Efficiency

Table 4: Results of ANOVA and Tukey's test for $\Delta \mathrm{b}$ at different times using FC

\begin{tabular}{|c|c|c|c|c|c|c|c|c|c|c|c|c|c|}
\hline \multirow[b]{2}{*}{ Groups } & \multicolumn{4}{|c|}{ 1st session } & \multicolumn{4}{|c|}{ 2nd session } & \multicolumn{4}{|c|}{1 year } & \multirow[b]{2}{*}{ ANOVA $^{\bullet}$} \\
\hline & Mean & $S D$ & $\#$ & $*$ & Mean & $S D$ & $\#$ & $*$ & Mean & $S D$ & $\#$ & * & \\
\hline $\mathrm{CN}$ & 1.00 & 0.49 & $A$ & $\mathrm{a}$ & 1.45 & 0.52 & $A$ & $a$ & 1.37 & 0.78 & $A$ & $a$ & $p=0.050(f=5.01)$ \\
\hline $\mathrm{CP}$ & -0.94 & 1.22 & B & a & -2.25 & 1.06 & B & $\mathrm{b}$ & -1.37 & 1.18 & B & a & $p=0.000 *(f=10.65)$ \\
\hline FC1 & -1.98 & 0.78 & C & a & -2.72 & 0.88 & B & $\mathrm{b}$ & -2.23 & 1.24 & C & $a b$ & $p=0.011^{*}(f=4.69)$ \\
\hline $\mathrm{FC} 2$ & -1.98 & 1.27 & C & a & -2.44 & 1.28 & B & a & -2.10 & 1.22 & $\mathrm{BC}$ & a & $p=0.321^{*}(f=1.14)$ \\
\hline FC3 & -2.19 & 1.44 & C & $\mathrm{a}$ & -2.25 & 1.17 & $\mathrm{~B}$ & a & -1.85 & 1.21 & $\mathrm{BC}$ & a & $p=0.401^{*}(f=0.92)$ \\
\hline ANOVA & \multicolumn{4}{|c|}{$p=0.000^{*}(f=47.28)$} & \multicolumn{4}{|c|}{$p=0.000^{*}(f=93.40)$} & \multicolumn{4}{|c|}{$p=0.000^{*}(f=55.28)$} & \\
\hline
\end{tabular}

"Different capital letters in columns indicate differences among the groups for each evaluation; *Different small letters in rows indicate differences among the readings for each group; ${ }^{\star}$ Results of ANOVA for the comparison among the groups for each evaluation ( $\left.d f=4\right)$;

-Results of ANOVA for the comparison among the readings for each group $(\mathrm{df}=2)$; ${ }^{*}$ Significant differences

Table 5: Results of ANOVA and Tukey's test for $\Delta b$ at different times using FG

\begin{tabular}{|c|c|c|c|c|c|c|c|c|c|c|c|c|c|}
\hline \multirow[b]{2}{*}{ Groups } & \multicolumn{4}{|c|}{ 1st session } & \multicolumn{4}{|c|}{ 2nd session } & \multicolumn{4}{|c|}{1 year } & \multirow[b]{2}{*}{ ANOVA $^{\bullet}$} \\
\hline & Mean & $S D$ & $\#$ & \& & Mean & $S D$ & $\#$ & * & Mean & $S D$ & $\#$ & \& & \\
\hline $\mathrm{CN}$ & 1.00 & 0.49 & $A$ & $\mathrm{a}$ & 1.45 & 0.52 & $A$ & $\mathrm{a}$ & 1.37 & 0.78 & $A$ & $\mathrm{a}$ & $p=0.050(f=5.01)$ \\
\hline $\mathrm{CP}$ & -0.94 & 1.22 & B & a & -2.25 & 1.06 & $\mathrm{~B}$ & $\mathrm{~b}$ & -1.37 & 1.18 & $\mathrm{~B}$ & a & $p=0.000^{*}(f=10.65)$ \\
\hline FG1 & -1.79 & 1.06 & C & a & -2.23 & 1.16 & $\mathrm{~B}$ & a & -1.89 & 1.44 & B & a & $p=0.336(f=1.10)$ \\
\hline FG2 & -1.44 & 0.70 & $\mathrm{BC}$ & a & -2.05 & 0.79 & $\mathrm{~B}$ & $\mathrm{~b}$ & -1.84 & 0.92 & $\mathrm{~B}$ & $a b$ & $p=0.011^{*}(f=4.65)$ \\
\hline FG3 & -1.11 & 0.96 & $\mathrm{~B}$ & a & -1.86 & 1.00 & $\mathrm{~B}$ & $\mathrm{~b}$ & -1.34 & 1.03 & $\mathrm{~B}$ & $a b$ & $p=0.010^{*}(f=4.80)$ \\
\hline ANOVA & \multicolumn{4}{|c|}{$p=0.000^{*}(f=44.46)$} & \multicolumn{4}{|c|}{$p=0.000^{*}(f=93.21)$} & \multicolumn{4}{|c|}{$p=0.000^{*}(f=49.29)$} & \\
\hline
\end{tabular}

\#Different capital letters in columns indicate differences among the groups for each evaluation; "Different small letters in rows indicate differences among the readings for each group; 'Results of ANOVA for the comparison among the groups for each evaluation ( $d f=4$ ); -Results of ANOVA for the comparison among the readings for each group ( $\mathrm{df}=2$ ); ${ }^{*}$ Significant differences

Table 6: Results of ANOVA and Tukey's test for $\Delta b$ at different times using MG

\begin{tabular}{|c|c|c|c|c|c|c|c|c|c|c|c|c|c|}
\hline \multirow[b]{2}{*}{ Groups } & \multicolumn{4}{|c|}{ 1st session } & \multicolumn{4}{|c|}{ 2nd session } & \multicolumn{4}{|c|}{1 year } & \multirow[b]{2}{*}{ ANOVA $^{\bullet}$} \\
\hline & Mean & $S D$ & \# & * & Mean & $S D$ & $\#$ & $*$ & Mean & $S D$ & $\#$ & $*$ & \\
\hline $\mathrm{CN}$ & 1.00 & 0.49 & $A$ & $a$ & 1.45 & 0.52 & $A$ & $\mathrm{a}$ & 1.37 & 0.78 & $A$ & $a$ & $p=0.050(f=5.01)$ \\
\hline $\mathrm{CP}$ & -0.94 & 1.22 & B & a & -2.25 & 1.06 & B & $b$ & -1.37 & 1.18 & B & a & $p=0.000 *(f=10.65)$ \\
\hline MG1 & -1.78 & 1.43 & C & a & -2.97 & 1.31 & $\mathrm{BC}$ & $\mathrm{b}$ & -1.76 & 1.50 & B & a & $p=0.000 *(f=7.66)$ \\
\hline MG2 & -2.08 & 1.17 & C & a & -3.16 & 1.26 & C & $\mathrm{b}$ & -2.11 & 1.33 & B & a & $p=0.000^{*}(f=7.71)$ \\
\hline MG3 & -1.38 & 1.07 & $\mathrm{BC}$ & $a$ & -2.82 & 1.29 & $\mathrm{BC}$ & $\mathrm{b}$ & -1.71 & 1.27 & $\mathrm{~B}$ & $\mathrm{a}$ & $p=0.000 *(f=12.31)$ \\
\hline ANOVA & \multicolumn{4}{|c|}{$p=0.000^{*}(f=37.60)$} & \multicolumn{4}{|c|}{$p=0.000^{*}(f=93.86)$} & \multicolumn{5}{|c|}{$p=0.000^{*}(f=42.02)$} \\
\hline
\end{tabular}

\#Different capital letters in columns indicate differences among the groups for each evaluation; "Different small letters in rows indicate differences among the readings for each group; ${ }^{\star}$ Results of ANOVA for the comparison among the groups for each evaluation (df $=4$ ); -Results of ANOVA for the comparison among the readings for each group ( $\mathrm{df}=2$ ); ${ }^{*}$ Significant differences

Table 7: Results of ANOVA and Tukey's test for $\Delta \mathrm{b}$ at different times using MC

\begin{tabular}{|c|c|c|c|c|c|c|c|c|c|c|c|c|c|}
\hline \multirow[b]{2}{*}{ Groups } & \multicolumn{4}{|c|}{ 1st session } & \multicolumn{4}{|c|}{ 2nd session } & \multicolumn{4}{|c|}{1 year } & \multirow[b]{2}{*}{ ANOVA $^{\bullet}$} \\
\hline & Mean & $S D$ & $\#$ & * & Mean & $S D$ & $\#$ & * & Mean & $S D$ & $\#$ & $*$ & \\
\hline $\mathrm{CN}$ & 1.00 & 0.49 & $A$ & $a$ & 1.45 & 0.52 & $A$ & $a$ & 1.37 & 0.78 & $A$ & $a$ & $p=0.050(f=5.01)$ \\
\hline $\mathrm{CP}$ & -0.94 & 1.22 & $B$ & a & -2.25 & 1.06 & B & $\mathrm{b}$ & -1.37 & 1.18 & $B$ & $a$ & $p=0.000^{*}(f=10.65)$ \\
\hline MC1 & -1.22 & 1.05 & $\mathrm{BC}$ & a & -2.54 & 1.08 & B & $\mathrm{b}$ & -1.35 & 1.36 & $B$ & a & $p=0.000^{*}(f=12.44)$ \\
\hline MC2 & -1.81 & 1.27 & CD & a & -2.87 & 1.45 & B & $b$ & -2.20 & 1.30 & C & $a b$ & $p=0.008^{*}(f=5.06)$ \\
\hline MC3 & -2.00 & 1.02 & $D$ & a & -2.73 & 1.05 & B & $b$ & -2.23 & 1.20 & $\mathrm{C}$ & $a b$ & $p=0.027^{*}(f=3.72)$ \\
\hline ANOVA & \multicolumn{4}{|c|}{$p=0.000^{*}(f=41.51)$} & \multicolumn{4}{|c|}{$p=0.000^{*}(f=92.53)$} & \multicolumn{4}{|c|}{$p=0.000^{*}(f=49.93)$} & \\
\hline
\end{tabular}

"Different capital letters in columns indicate differences among the groups for each evaluation; "Different small letters in rows indicate differences among the readings for each group; ${ }^{\star}$ Results of ANOVA for the comparison among the groups for each evaluation $(\mathrm{df}=4$ ); -Results of ANOVA for the comparison among the readings for each group ( $\mathrm{df}=2$ ); ${ }^{*}$ Significant differences

the second application, nonsignificant differences were observed in relation to the positive control group. For concentrations 2 and 3, no color regression was observed.

In order to determine which activator was the most effective, the $\Delta \mathrm{b}$ data, independent of the concentration, were compared using ANOVA and Tukey's test. The results are shown in Table 8 . It can be seen that after the first application, the catalysts FC, FS, MG, and MC showed higher effects than the positive control group. After the second application, only MG was different from the positive control group. After 1 year, only FS showed a significantly higher effect than the positive control group. 
Table 8: Results of the $\Delta \mathrm{b}$ values comparisons among the different experimental groups and the control group

\begin{tabular}{|c|c|c|c|c|c|c|c|c|c|c|c|c|c|c|c|c|}
\hline \multicolumn{6}{|c|}{ 1st session } & \multicolumn{6}{|c|}{ 2nd session } & \multicolumn{5}{|c|}{1 Year } \\
\hline \multirow{2}{*}{$\begin{array}{l}\text { Groups } \\
\text { FC }\end{array}$} & \multirow{2}{*}{$\begin{array}{l}\text { Mean } \\
-2.05\end{array}$} & \multirow{2}{*}{$\frac{S D}{1.19}$} & \multicolumn{3}{|c|}{$\begin{array}{l}\text { Homogeneous } \\
\text { sets* }\end{array}$} & \multirow{2}{*}{$\begin{array}{l}\text { Groups } \\
\text { MG }\end{array}$} & \multirow{2}{*}{$\begin{array}{l}\text { Mean } \\
-2.98\end{array}$} & \multirow{2}{*}{$\frac{S D}{1.28}$} & \multicolumn{3}{|c|}{$\begin{array}{l}\text { Homogeneous } \\
\text { sets* }\end{array}$} & \multirow{2}{*}{$\begin{array}{l}\text { Groups } \\
\text { FS }\end{array}$} & \multirow{2}{*}{$\begin{array}{l}\text { Mean } \\
-2.65\end{array}$} & \multirow{2}{*}{$\begin{array}{l}S D \\
1.46\end{array}$} & \multicolumn{2}{|c|}{$\begin{array}{l}\text { Homogeneous } \\
\text { sets* }\end{array}$} \\
\hline & & & $A$ & - & - & & & & A & - & & & & & $A$ & - \\
\hline FS & -1.81 & 1.08 & $A$ & $B$ & - & $\mathrm{MC}$ & -2.71 & 1.20 & $A$ & B & & $\mathrm{FC}$ & -2.06 & 1.22 & - & $B$ \\
\hline MG & -1.75 & 1.25 & $A$ & $B$ & - & $\mathrm{FC}$ & -2.47 & 1.13 & - & B & $\mathrm{C}$ & MC & -1.93 & 1.34 & - & B \\
\hline MC & -1.68 & 1.16 & $A$ & $B$ & - & FS & -2.34 & 1.26 & - & B & $\mathrm{C}$ & MG & -1.86 & 1.37 & - & B \\
\hline FG & -1.45 & 0.95 & - & $B$ & $\mathrm{C}$ & PC & -2.25 & 1.06 & - & B & $\mathrm{C}$ & FG & -1.69 & 1.17 & - & B \\
\hline PC & -0.94 & 1.22 & - & 一 & $\mathrm{C}$ & $\mathrm{FG}$ & -2.04 & 0.99 & - & - & $\mathrm{C}$ & $\mathrm{PC}$ & -1.37 & 1.18 & - & B \\
\hline
\end{tabular}

${ }^{*}$ Groups followed by the same letter do not present significant differences; "Significant differences

\section{DISCUSSION}

Tooth color measures are usually based on the CIE Lab color system. In this tridimensional system, the $\mathrm{L}^{*}$ axis represents the degree of lightness within a sample, the $a^{*}$ plane represents the degree of green/red color, while the $b^{*}$ plane represents the degree of blue/yellow color. Since the yellowish color has been strongly related to the subjective color change perception by the patients resulting from bleaching outcomes, ${ }^{36}$ in the present study the $b^{*}$ was the coordinate used for data analysis.

In this study, the bleaching produced by the hydrogen peroxide gel without any catalyzer showed a color change significantly higher than the negative control group, which remained immersed in artificial saliva, proving the effectiveness of the experimental gel formulation. The second session resulted in a color change in relation to the baseline significantly higher than the first, showing the accumulative bleaching effect. On the other hand, an expressive color regression was observed after 1 year, maybe because the chemical bonding brooked by the oxidative reaction was restored, since the samples remained immersed in artificial saliva and were not exposed to any additional chromogenic agents, generally present inside the oral cavity. ${ }^{37}$

Although there are a limited number of studies in dentistry analyzing the effect of chemical activators, they have been extensively studied in the industrial process for bleaching of wooden pulp, raw cotton, cloth, dish washing, and the treatment of polluted water. ${ }^{38-40}$ The challenges present for dental bleaching are basically the same as for the industrial process, since the basic active agent, hydrogen peroxide, is the same, and the chemical structure of the chromogens are similar.

Some transition metals have been widely used in the industrial process for the bleaching catalysis. The effect of the metallic salts, acting as catalyzers, are related to the interference with the activation energy of the dissociation reaction of hydrogen peroxide, increasing the speed of the reaction and reducing the kinetic energy required by the molecules of the reagents to start the reaction, providing a path of low energy. ${ }^{24}$
The use of iron to catalyze the decomposition of hydrogen peroxide is well documented in the literature with the name of Fenton reaction. ${ }^{41}$ Although there are other theories to explain the action of iron, such as the formation of $\mathrm{FeO}^{2+}$ or complexes with peroxide, the basic principles of the Fenton reaction with the formation of free radicals are the most accepted. ${ }^{42,43}$ This study tested different substances that are source of iron ions. Dahlstrom et al showed that in presence of iron, a higher number of free radicals are formed. ${ }^{44}$

The FS is a substance commonly used in medications for the treatment of iron deficiency anemia, because the absorption rate of ferrous ions are higher than the ferric ions, making it useful for humans. ${ }^{45}$ In a pilot study, the FS showed the most intense effect in promoting the release of oxygen bubbles inside the bleaching gel. For this reason, the concentration used for this study was 10 times smaller than the other catalyzers. The results showed that after one application, significant differences were observed for concentrations 2 and 3, with a reduction of the $b^{*}$ value two times more than the positive control group (approx. 1 unit of $\Delta b$ ), rejecting the null hypotheses. This change means that the samples became less yellow. After the second session, nonsignificant differences were observed for the catalyzed groups in relation to the positive control. This may be related to the fact that the alkaline solutions containing FS were prepared immediately before the first bleaching session, and remained stored for 7 days before being used again. Some change may have happened, such as ions' precipitation by the formation of iron hydroxide, reducing its effects. The precipitation of ferrous ions was observed by Nicoll and Smith. ${ }^{46}$ Maybe the addition of some kind of stabilizer could have prevented this precipitation, as suggested by Freedman..$^{22}$ If a new activator solution had been prepared before the second application, probably different results would have been obtained.

After 1 year, the groups activated with FS showed a significant difference in relation to the positive control of approximately one unit of $\Delta \mathrm{b}$, avoiding the color regression observed in the control group. It seems that the 
oxidation promoted by the catalyst was more intense and complete than that observed in the control group, maybe because of the higher amount of free radicals formed by the Fenton reaction. Probably the use of a higher concentration of FS could result in a more expressive color change, but it is necessary to do additional studies to prove this hypothesis.

Ferric chloride is employed as flocculants in wastewater treatment and water purification. In dentistry, it was used as an ingredient of the acidic conditioner 10:3, an association of $10 \%$ citric acid and $3 \% \mathrm{FC}$, indicated for dentin etching for adhesive procedures. ${ }^{47}$ The addition of this activator doubled the mean $b^{*}$ values in relation to the positive control. However, after the second application, this effect was not observed, probably because of precipitation of iron ions. The color regression was avoided. The FC also participates in the Fenton reaction, generating more active oxygen species.

When the Fenton reaction occurs, the initial precursor is the ferrous ions $\left(\mathrm{Fe}^{2+}\right)$, which react with hydrogen peroxide and promote the formation of free radicals. During this reaction it is converted to ferric ions $\left(\mathrm{Fe}^{3+}\right)$. Those react again with peri-hydroxyl radicals and return to the condition of ferrous ions, feeding back into this process, as can be seen in the Equations 4 to 6 . Therefore, the use of FS can be more convenient to the reaction in relation to ferric salts, because it starts the process. When the FS and FC were compared after 1 year, it was observed that FS was more efficient for the concentrations tested (Tables 3 and 4).

$$
\begin{aligned}
& \mathrm{Fe}^{2+}+\mathrm{H}_{2} \mathrm{O}_{2} \rightarrow \mathrm{Fe}^{3+}+\mathrm{HO}^{\bullet}+\mathrm{HO}^{-} \\
& \mathrm{HO}^{\bullet}+\mathrm{H}_{2} \mathrm{O}_{2} \rightarrow \mathrm{HO}_{2}+\mathrm{H}_{2} \mathrm{O} \\
& \mathrm{Fe}^{3+}+\mathrm{HO}_{2} \rightarrow \mathrm{Fe}^{2+}+\mathrm{O}_{2}+\mathrm{H}^{+}
\end{aligned}
$$

Nicoll and Smith evaluated the effect of the kind of anion connected to iron on hydrogen peroxide stability. ${ }^{46}$ Equivalent concentrations of iron ions from sulphate had a higher catalytic effect than when they were added as chloride. The percentage of residual peroxide inside the solution was $79 \%$ for sulphate and $92 \%$ for chloride. The sulphate cation can react with traces of alkaline earth metals in the solution, which stabilize the peroxide, neutralizing its effect. Those observations corroborate with the findings of this study.

Bishop et al tested ferric and ferrous salts, in different $\mathrm{pHs}$ and temperatures. ${ }^{40}$ They observed that when ferrous salt is used, the hydroxyl free radicals are produced immediately by the quick reaction between the ferrous ions $\left(\mathrm{Fe}^{2+}\right)$ and hydrogen peroxide (dissociation

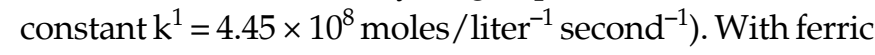
salts, the hydroxyl free radical is produced in a two-step process, with the slow reaction between the ferric ion $\left(\mathrm{Fe}^{3+}\right)$ and the hydrogen peroxide (dissociation constant $\mathrm{k}^{2}=1.1 \times 10^{24}$ moles $/$ liter $^{-1}$ second $^{-1}$ ), producing ferrous ions, which reacts more quickly with more hydrogen peroxide. They observed that the reaction with ferric ions require a higher temperature to get the maximum efficiency, beyond $65^{\circ} \mathrm{C}$, while with ferrous ions are efficient at room temperature. Another factor that can have influenced the efficacy of this reaction is the kind of alkalizing agent used, because of its reaction with $\mathrm{Fe}^{3+}$ ions. ${ }^{48}$ Additional studies are necessary to analyze this hypothesis.

The FG is a complex where the ferrous ions are associated with the gluconate ligand. It is also used for the treatment of anemia and in the food industry. Although previous studies showed that the addition of FG significantly increased the bleaching effect, ${ }^{10,34}$ in this study, it was not effective in improving the bleaching effect for all concentrations tested, nor in preventing the yellowish regression, as observed for FS and FC. It is possible that the reactivity of the ferrous ion inside the complex is lower than the free ions obtained from the other sources. Another explanation could be related to the molar mass of the FG $(446.1 \mathrm{gm} / \mathrm{mol})$ in relation to FS (151.908 gm/mol) and FC (162.2 gm/mol). For the same amount of weight of the three catalyzers, a small amount of iron atoms is present at the first, because the gluconate molecules have a higher weight than that anions connected to iron atoms inside the other substances. Therefore, maybe a higher concentration would produce more pronounced results. Additional studies are needed to analyze this hypothesis.

The MC is used in medicine as a contrast for magnetic resonance exams and in agriculture as a micronutrient of plants. It releases the $\mathrm{Mn}^{2+}$ cation in solution. The $\mathrm{Mn}^{3+}$ produces an acceleration of hydrogen peroxide decomposition and formation of free radicals, being converted into $\mathrm{Mn}^{2+}$ during this process. As the manganese chloride releases $\mathrm{Mn}^{2+}$, it must be first converted in $\mathrm{Mn}^{3+}$ to start the reaction, consuming part of the free radicals formed, which makes the reaction slower (Equations 7-10). When applied as a catalyzer, effects significantly higher than the control was observed for concentrations 2 and 3 after one application and 1 year, although it was not observed after the second session, maybe because of its instability inside the alkaline solution. On the other hand, concentrations 2 and 3 also prevented the regression of the yellowish color. Positive results with this activator was observed in another study. ${ }^{21}$

$$
\begin{aligned}
& \mathrm{Mn}^{3+}+\mathrm{H}_{2} \mathrm{O}_{2} \leftrightarrow \mathrm{Mn}^{2+}+\mathrm{H}_{2} \mathrm{O}_{2}^{+\bullet} \\
& \mathrm{Mn}^{3+}+\mathrm{H}_{2} \mathrm{O}_{2}^{+\bullet} \rightarrow \mathrm{Mn}^{2+}+2 \mathrm{H}^{+}+\mathrm{O}_{2} \\
& \mathrm{H}_{2} \mathrm{O}_{2}+\mathrm{H}_{2} \mathrm{O}_{2}^{+\bullet} \rightarrow \mathrm{OH}^{\bullet}+\mathrm{H}_{3} \mathrm{O}^{+}+\mathrm{O}_{2} \\
& \mathrm{Mn}_{2}{ }^{+}+\mathrm{OH}^{\bullet} \leftrightarrow \mathrm{Mn}^{3+}+\mathrm{OH}^{-}
\end{aligned}
$$

According to Rerek et $\mathrm{al}^{49}$ under alkaline conditions, the manganese ions precipitate very quickly into 
manganese hydroxide and manganese dioxide. The solution prepared in the current study had a $\mathrm{pH}$ of 9.7 . Freedman ${ }^{22}$ suggested the addition of tretrasodium EDTA as a chelate to prevent this precipitation. The study of Rerek et $\mathrm{al}^{49}$ showed that the pure manganese chloride $\left(\mathrm{MnCl}_{2}\right)$ is less effective when manganese is associate with a ligand, because it can prevent the precipitation.

The manganese gluconate is a complex having a central atom of manganese and a ligand gluconate, being used as a nutritional complement for humans. It can also be used as a component of the powder detergent formulation for laundry, increasing the efficacy of stain removal. ${ }^{50}$ Promising results have been shown with the association of this agent with hydrogen peroxide, since it was demonstrated that it accelerates the decomposition of hydrogen peroxide, with an intensification of the effect resulting from the increase of concentration. ${ }^{49}$ Its use as an activator of hydrogen peroxide bleaching in darkened teeth was previously reported, with an increase of the bleaching effect 1.8 to 8 times in relation to a formulation without the activator. ${ }^{18}$ Nevertheless, it has been shown that a large amount of this agent is needed to produce an increase of the hydrogen peroxide bleaching effect.

In our study, concentrations 1 and 2 showed more intense results than the positive control after one application, although after the second application, just concentration 2 was efficient. After 1 year, nonsignificant effects of this catalyst were observed in relation to the positive control, and color regression was observed. In a similar way to FG, the higher molar weight of this molecule $(481.27 \mathrm{gm} / \mathrm{mol})$ in relation to manganese chloride (125.844 gm/mol) may have produce a smaller availability of $\mathrm{Mn}$ atoms for the reaction with the peroxide. Maybe if higher concentrations had been applied, more favorable results could be obtained. Additionally, some studies showed that a limitation of this system is that its performance is not adequate in temperatures close to that of oral cavity, but is increased in higher temperatures $\left(>40^{\circ} \mathrm{C}\right)$ and a large amount must be added in the formulation to have significant effects on hydrogen peroxide decomposition. ${ }^{49,51}$

Maybe the use of higher concentrations of chemical activator could produce a more significant result for all catalysts tested, since the increase of concentration of a catalyst based on metallic ions increased pro rata the decomposition of hydrogen peroxide. ${ }^{45}$ The determination of the ideal concentration for each catalyst would need a higher number of experimental groups and must be evaluated in additional studies.

Previous studies showed positive results with the use of metallic salts associated with high concentrated hydrogen peroxide bleaching gels on dental bleaching. ${ }^{23,24}$
Maybe the limited effect observed in this study was due to the current lack of knowledge about the ideal concentration of each catalyst, the optimal $\mathrm{pH}$ for the reaction, and the stability of these salts on the solutions. Therefore, additional studies are necessary.

Many studies have shown that the $\mathrm{pH}$ in which the bleaching reaction with hydrogen peroxide occurs can influence the efficiency of the process, improving the bleaching effect. ${ }^{10-14}$ In higher $\mathrm{pH}$, a higher amount of peri-hydroxyl ions are formed, which increases the formation of free radicals. ${ }^{13,38,52}$ However, as can be seen in Table 2, the addition of the catalyst in all formulations did not significantly interfere with the $\mathrm{pH}$ of the alkaline solutions or bleaching gels, indicating that the variation of the effects can be due the action of the metallic ions and not because of the $\mathrm{pH}$.

According to Bishop et $\mathrm{al}^{40}$ in order to avoid the precipitation of the iron ions, the Fenton reaction should occur preferably between $\mathrm{pH} 3$ and 5 . If the $\mathrm{pH}$ is too high, the ions $\mathrm{Fe}^{2+}$ and $\mathrm{Fe}^{3+}$ will precipitate into iron hydroxide and promote the decomposition of hydrogen peroxide in water and oxygen, do not generating oxygen active species. ${ }^{46}$ Taking that into account, the $\mathrm{pH}$ of the bleaching gel tested was in an acceptable range, near 5.5. On the other hand, the alkaline solution used in the dissolution of the salts was around 9.9, potentially promoting the precipitation and inactivation of the ions. Maybe metallic complexes with a higher stability in alkaline solutions would allow more expressive results.

From the results of this study, it can be seen that the use of the chemical catalyst showed promising results, in relation to the efficiency of dental bleaching, especially in the yellowish color reduction. On the other hand, the determination of the ideal concentration of each catalyst, the kind of alkaline agent, and the stability in the solution must be further studied in order to formulate more efficient products. The concern about the toxicity and the potential of pulpal irritation by the catalyst and the formation of more free radicals also need additional studies, as well as its effects over the structural integrity of enamel and dentin. Further clinical studies must confirm the effectiveness of those agents in producing bleaching outcomes more quickly and effective.

\section{CONCLUSION}

Within the limitations of this study, it was concluded that:

- The addition of the catalyst FS, FC, MG, and MC significantly influenced the bleaching effect on the reduction of the yellowish color.

- The concentration of the catalyst has a significant influence on the bleaching effect. 
- The use of FS, FC, FG, and MG increase the color stability of bleached specimens.

- After 1 year, FS was the most efficient catalyst on the yellowish color reduction.

\section{REFERENCES}

1. McEvoy SA. Chemical agents for removing intrinsic stains from vital teeth. II. Current techniques and their clinical application. Quintessence Int 1989;20(6):379-384.

2. Pignoly C, Camps L, Susini G, About I, Camps J. Influence of in-office whitening gel $\mathrm{pH}$ on hydrogen peroxide diffusion through enamel and color changes in bovine teeth. Am J Dent 2012;25(2):91-96.

3. Kawamoto K, Tsujimoto Y. Effects of the hydroxyl radical and hydrogen peroxide on tooth bleaching. J Endod 2004;30(1): 45-50.

4. Buchalla W, Attin T. External bleaching therapy with activation by heat, light or laser-a systematic review. Dental Materials 2007;23(5):586-596.

5. AlShethri S, Matis BA, Cochran MA, Zekonis R, Stropes M. A clinical evaluation of two in-office bleaching products. Oper Dent 2003;28(5):488-495.

6. Marson FC, Sensi LG, Vieira LC, Araujo E. Clinical evaluation of in-office dental bleaching treatments with and without the use of light-activation sources. Oper Dent 2008;33(1):15-22.

7. Bowles WH, Ugwuneri Z. Pulp chamber penetration by hydrogen peroxide following vital bleaching procedures. J Endodont 1987;13(8):375-377.

8. Wiegand A, Vollmer D, Foitzik M, Attin R, Attin T. Efficacy of different whitening modalities on bovine enamel and dentin. Clinical Oral Investigations 2005;9(2):91-97.

9. Hardman PK, Moore DL, Petteway GH. Stability of hydrogen peroxide as a bleaching agent. Gen Dent 1985 Mar-Apr;33(2): 121-122.

10. Young N, Fairley P, Mohan V, Jumeaux C. A study of hydrogen peroxide chemistry and photochemistry in tea stain solution with relevance to clinical tooth whitening. J Dent 2012;40 (Suppl 2):e11-e16.

11. Chen JH, Xu JW, Shing CX. Decomposition rate of hydrogen peroxide bleaching agents under various chemical and physical conditions. J Prosthet Dent 1993;69(1):46-48.

12. Xu B, Li Q, Wang Y. Effects of $\mathrm{pH}$ values of hydrogen peroxide bleaching agents on enamel surface properties. Oper Dent 2011;36(5):554-562.

13. Taher AMM, Cates DM. Bleaching cellulose: Part I. A free radical mechanism. Textile Chemist and Colorist 1975;7(12):5.

14. Frysh H, Bowles WH, Baker F, Rivera-Hidalgo F, Guillen G. Effect of $\mathrm{pH}$ on hydrogen peroxide bleaching agents. J Esthet Dent 1995;7(3):130-133.

15. Torres CR, Crastechini E, Feitosa FA, Pucci CR, Borges AB. Influence of $\mathrm{pH}$ on the effectiveness of hydrogen peroxide whitening. Oper Dent 2014;39(6):E261-E268.

16. Feinman RA, Madray G, Yarborough D. Chemical, optical, and physiologic mechanisms of bleaching products: a review. Pract Periodontics Aesthet Dent 1991;3(2):32-36.

17. Viscio D, Gaffar A, Fakhry-Smith S, Xu T. Present and future technologies of tooth whitening. Compend Contin Educ Dent 2000 Suppl(28):S36-43; quiz S49.

18. Gaffar A, Fakhry-Smith S. Oral compositions having accelerated tooth whitening effect. USA; 1997.
19. Mattos IL, Shiraishi KA, Braz AD, Fernandes JR. Peróxido de hidrogênio: importância e determinação. Quim Nova 2003;26(3):7.

20. Zhao J; Whitening compound. United States of America 2005.

21. Banerjee A, Friedman J. Dental bleaching gel composition, activator system and method for activating a dental bleaching gel. USA; 2002.

22. Freedman B. Booster and activator composition for toothwhitening agents. USA; 2004.

23. Travassos AC, Torres RGC, Borges AB, Barcellos DC. In vitro assessment of chemical activation efficiency during in-office dental bleaching. Oper Dent 2010;35(3):287-294.

24. Torres CR, Wiegand A, Sener B, Attin T. Influence of chemical activation of a $35 \%$ hydrogen peroxide bleaching gel on its penetration and efficacy—in vitro study. J Dent 2010;38(10):8.

25. Jones AH, Diaz-Arnold AM, Vargas MA, Cobb DS. Colorimetric assessment of laser and home bleaching techniques. J Esthet Dent 1999;11(2):87-94.

26. Harris EF, Hicks JD. A radiographic assessment of enamel thickness in human maxillary incisors. Arch Oral Biol 1998;43(10):825-831.

27. Murray PE, Stanley HR, Matthews JB, Sloan AJ, Smith AJ. Age-related odontometric changes of human teeth. Oral Surg Oral Med Oral Pathol Oral Radiol Endod 2002;93(4):474-482.

28. Joiner A. Tooth colour: a review of the literature. J Dent 2004;32 (Suppl 1):3-12.

29. Lee YK, Lu H, Powers JM. Changes in opalescence and fluorescence properties of resin composites after accelerated aging. Dent Mater 2006;22(7):653-660.

30. Ragain JC Jr, Johnston WM. Accuracy of Kubelka-Munk reflectance theory applied to human dentin and enamel. J Dent Res 2001;80(2):449-452.

31. Caneppele TM, Borges AB, Torres CR. Effects of dental bleaching on the color, translucency and fluorescence properties of enamel and dentin. Eur J Esthet Dent 2013;8(2):200-212.

32. Gohring TN, Zehnder M, Sener B, Schmidlin PR. In vitro microleakage of adhesive-sealed dentin with lactic acid and saliva exposure: a radio-isotope analysis. J Dent 2004;32(3):235-240.

33. Batista GR, Arantes PT, Attin T, Wiegand A, Torres CR. Effect of chemical activation of $10 \%$ carbamide peroxide gel in tooth bleaching. Eur J Esthet Dent 2013;8(1):104-117.

34. Batista GR, Barcellos DC, Torres CR, Goto EH, Pucci CR, Borges $\mathrm{AB}$. The influence of chemical activation on tooth bleaching using 10\% carbamide peroxide. Oper Dent 2011; 36(2):162-168.

35. USP. The united states pharmacopeia: The national formulary. Rockville: The United States Pharmacopeial Convention; 2006.

36. Gerlach RW, Barker ML, Sagel PA. Objective and subjective whitening response of two self-directed bleaching systems. Am J Dent 2002;15 Spec No:7A-12A.

37. Maiolo K, Marin PD, Bridges TE, Heithersay GS. Evaluation of a combined thiourea and hydrogen peroxide regimen to bleach bloodstained teeth. Aust Dent J 2007;52(1):33-40.

38. Abdel-Halima ES, Al-Deyaba SS. One-step bleaching process for cotton fabrics using activated hydrogen peroxide. Carbohydrate Polymers 2013;92:5.

39. Dannacher JJ. Catalytic bleach: Most valuable applications for smart oxidation chemistry. J Molecular Catalysis 2006;251:7.

40. Bishop DF, Stern G, Fleischman M, Marshall LS. Hydrogen peroxide catalytic oxidation of refractory organics in municipal waste waters. I and EC Process Design and Development 1968;7(1):7. 
41. Fenton HJH. Oxidation of tartaric acid in presence of iron. J Chem Soc Transac 1894;65:12.

42. Kremer ML. The Fenton reaction: dependence of the rate on pH. J Phys Chem A 2003;107:7.

43. Kremer ML. Oxidation-reduction step in catalytic decomposition of hydrogen peroxide by ferric ions. Trans Faraday Soc 1963;59:7.

44. Dahlstrom SW, Heithersay GS, Bridges TE. Hydroxyl radical activity in thermocatalytically bleached root-filled teeth. Endod Dent Traumatol 1997;13(3):119-125.

45. Abbot J, Brown DG. Kinetics of iron-catalyzed decomposition of hydrogen peroxide in alcaline solution. Int J Chem Kinet 1990;22:11.

46. Nicoll WD, Smith AF. Stability of dilute alkaline solutions of hydrogen peroxide. Ind Eng Chem 1955;47(12):5.
47. Nakabayashi N. Adhesive bonding with 4-META. Oper Dent 1992;(Suppl 5):125-130.

48. Ferreira AMC, Duarte LL. The effect of triethanolamine on the Iron(III)—catalysed decomposition of hydrogen peroxide. J Coordination Chemistry 1991;24(4):11.

49. Rerek ME, Weil I, Hill M. Kinetics and mechanism of the Mn(III) - gluconate catalyzed decomposition of hydrogen peroxide. Coordination Chemistry Reviews 1990;105:251.

50. Chapple AP; Lever Brothers Company, Division of Conopco, Inc., assignee. Bleach catalyst composition. USA. 1996.

51. Jureller SH, Kerschner JL. Lever Brothers Company, Division of Conopco Inc., assignee. Manganese catalyst for activating hydrogen peroxide bleaching. USA. 1993.

52. Brooks RE, Moore SB. Alkaline hydrogen peroxide bleaching of cellulose. Cellulose 2000;7:23. 